Check for updates

Cite this: RSC Adv., 2017, 7, 53076

Received 5th October 2017

Accepted 13th November 2017

DOI: $10.1039 / c 7 r a 10933 d$

rsc.li/rsc-advances

\section{Amino organosilane grafted ordered mesoporous alumina with enhanced adsorption performance towards $\mathrm{Cr}(\mathrm{vI}) \dagger$}

\begin{abstract}
Xin Jin, $^{\text {a }}$ Weiquan Cai ${ }^{*}{ }^{* a b}$ and Zhijun Cai ${ }^{\mathrm{C}}$
Ordered mesoporous alumina (MA) was successfully modified with three amino organosilanes including 3aminopropyltriethoxysilane (1N), $N$-( $\beta$-aminoethyl)- $\gamma$-aminopropylmethylbimethoxysilane $(2 \mathrm{~N}$ ) and $\mathrm{N}$-3trimethoxysilylpropyldiethylenetriamine $(3 N)$ via a facile grafting method, and the as-prepared amino organosilane grafted $M A-1 N, M A-2 N$ and $M A-3 N$ show enhanced adsorption performance towards $\mathrm{Cr}(\mathrm{VI})$ removal from wastewater. Their physicochemical properties and the MA before modification were comparatively characterized by FT-IR, TEM, XRD, $\mathrm{N}_{2}$ adsorption-desorption, CHNS elemental analysis, zeta potential measurements and XPS. Their adsorption performance was also comparatively studied along with the effect of contact time, adsorption isotherms, multi-metal ion adsorption, interference of co-existing anions and regeneration ability in batch experiments. It was found that their adsorption kinetics data were better fitted by the pseudo-second order model; adsorption isotherms were better described by the Langmuir isotherm for $M A-1 N$, the Freundlich isotherm for $M A-2 N$ and the Temkin isotherm for MA-3N. Among them, MA-2N shows the maximum adsorption capacity of $137.9 \mathrm{mg} \mathrm{g}^{-1}$ which is more than twice the $59.4 \mathrm{mg} \mathrm{g}^{-1}$ of MA. The residual concentration of $\mathrm{Cr}(\mathrm{VI})$ with a concentration of $50 \mathrm{mg} \mathrm{L}^{-1}$ when treated with $\mathrm{MA}-2 \mathrm{~N}$ meets the emission standard of the World Health Organization (WHO). Moreover, MA-2N shows better selectivity toward $\mathrm{Cr}(\mathrm{VI})$, and can reduce relatively more $\mathrm{Cr}(\mathrm{VI})$ to low toxicity $\mathrm{Cr}(\mathrm{III})$. More results were found that $\mathrm{Cr}(\mathrm{VI})$ is adsorbed on the surface through a monodentate ligand or bidentate ligand, and then $\mathrm{Cr}(\mathrm{VI})$ is reduced to $\mathrm{Cr}(\mathrm{III})$ by an adjacent electron donor, after which $\mathrm{Cr}(\mathrm{III})$ is co-precipitated with the adsorbents. All the amine-grafted samples show good reusability for 5 cycles. These results indicated that the amino organosilane grafted ordered MA with high adsorption capacity, good selectivity and favourable reusability is a promising candidate for $\mathrm{Cr}(\mathrm{VI})$ removal, in combination with its low cost and energy saving preparation process.
\end{abstract}

\section{Introduction}

Heavy metals are persistent, bio-accumulative and very hazardous substances with a deleterious effect on the fauna and flora of lakes and streams, and therefore have to be intensively removed before discharge. Among them, hexavalent chromium $\mathrm{Cr}(\mathrm{vI})$ is commonly found in wastewaters originating from the chromic salt industry, alloying electroplating and metal polishing. ${ }^{1} \mathrm{Cr}(\mathrm{vI})$ is a highly soluble, reactive and mobile species in aquatic systems, thus exerting carcinogenicity and toxicity in

${ }^{a}$ School of Chemistry, Chemical Engineering and Life Sciences, State Key Laboratory of Silicate Materials for Architectures, Wuhan University of Technology, 205 Luoshi Road, Wuhan 430070, P. R. China. E-mail: caiwq@whut.edu.cn; Fax: +86-27-87749379; Tel: $+86-27-87749379$

${ }^{b}$ School of Chemistry and Chemical Engineering, Guangzhou University, 230 Guangzhou University City Outer Ring Road, Guangzhou 510006, China

'International School of Materials Science and Engineering, Wuhan University of Technology, 205 Luoshi Road, Wuhan 430070, P. R. China

$\dagger$ Electronic supplementary information (ESI) available. See DOI: 10.1039/c7ra10933d biological systems due to its strong oxidizing properties. ${ }^{2}$ Up to now, various methods have been developed to treat $\operatorname{Cr}(\mathrm{vI})$ wastewater, including separation, chemical precipitation, reduction, ion exchange and adsorption. Among them, adsorption is prominent for its advantages of low cost, high efficiency, easy operation and low secondary pollution impact. However, it is still difficult to decrease the residual $\mathrm{Cr}(\mathrm{vI})$ concentration under its maximum permissible discharge standard of $0.05 \mathrm{mg} \mathrm{L}^{-1}$ recommended by the World Health Organization (WHO) in drinking water. Furthermore, instead of a single component solution, industrial wastewater usually contains a variety of anions and cations. Therefore, developing adsorbent with high adsorption capacity, low residual concentration below the WHO limit and good selectivity toward multiple heavy metal ions is of practical meaning.

In last two decades, various mesoporous materials were developed and applied to heavy metal adsorption. ${ }^{3,4}$ They are of high surface area, large pore volume, hydroxy-rich surface and highly ordered structures, which are suitable for adsorption and further modification. ${ }^{6,7}$ Among them, alumina is a popular 
adsorptive and catalytic material because of its excellent physical and textural properties when compared to other transitional inorganic oxides. ${ }^{8}$ Its amphoteric nature makes it one of the best candidates to be widely used in water treatment, especially in the adsorption area of anions. ${ }^{9}$ Modified alumina with amino groups is a common method to enhance its adsorption performance because amino groups have good affinity towards $\mathrm{Cr}(\mathrm{vI}) .{ }^{\mathbf{1 0 1 1}}$ Dating back to $1990 \mathrm{~s}$, the functionalization of mesoporous materials by grafting method came into the sight of heavy metal removal. X. Feng et al. ${ }^{12}$ synthesized thiol-functionalized ordered mesoporous silica, and found that it was equipped with high metal loading capacity and high selectivity towards $\mathrm{Hg}$ (II). It can bind metallic, inorganic, organic, charged, and neutral compounds and can be used in a variety of media such as water, oil and gas. The advancement of the grafting technology provides a unique opportunity to introduce molecular binding sites and to rationally design the surface properties of mesoporous materials. Therefore, materials are endowed with diversity of functions through varying pendant groups, meeting different requirements. Amino-organosilanes are easily hydrolyzed and silylanized due to their alkaline characteristic; alumina is equipped with abundant $-\mathrm{OH}$ groups on its surface and able to adsorb $\mathrm{H}_{2} \mathrm{O}$ molecule by hydrogen bond, affording large amounts of active groups for reacting. As a result, the organic-inorganic hybrid materials are prepared and chemical bond forms to guarantee stability during adsorption process. Accordingly, the advantages of alumina retain, and its adsorption performance is improved.

Grafting by means of toluene or acetone reflux under heating condition is the most common technique to cross-link organosilanes on the adsorbent surface, ${ }^{6,12,13}$ whereas a grafting method that magnetically stirs at room temperature in ethanol was proved to be resultful and turned out to be feasible, practical and environmentally friendly., ${ }^{5,14}$ Several kinds of amino organosilanes were used as modifying agent to enhance the performance of adsorbents. ${ }^{14,15}$ The amino groups can be protonated after cross-linked on the alumina surface. However, to the best of our knowledge, we have not found studies on the modification of ordered MA with those amino oragnosilanes that focus on their adsorption ability in $\mathrm{Cr}(\mathrm{vI})$ removal.

Herein, amino functionalized ordered MAs were successfully prepared by a green method using environmental ethanol instead of acetone or toluene as solvent, to mildly graft amino organosilane. The as-prepared organic-inorganic hybrids show much better adsorption performance towards $\mathrm{Cr}(\mathrm{vI})$ than the original ordered MA. It is worth mentioning that the residual concentration of $\mathrm{Cr}(\mathrm{vI})$ treated by our adsorbents not only meets the wastewater discharge Standard GB 8978-1996 (0.5 mg L $\left.{ }^{-1}\right)$ of China, but also meets the maximum permissible discharge standard of $\mathrm{Cr}(\mathrm{vI})$ in drinking water $\left(0.05 \mathrm{mg} \mathrm{L}^{-1}\right)$ recommended by the WHO. Hence, the as prepared hybrids are competent candidates that could be used in the field of $\operatorname{Cr}(\mathrm{vI})$ removal from waste water.

\section{Experimental section}

\subsection{Materials}

$(\mathrm{EO})_{20}(\mathrm{PO})_{70}(\mathrm{EO})_{20}$, one of the triblock copolymers Pluronic P123 (MW $=5800 \mathrm{Da}$ ) was purchased from Sigma Aldrich. Other chemicals used are of analytical reagent grade without further purification. Nitric acid, anhydrous ethanol, aluminium isopropoxide, inorganic salts including $\mathrm{K}_{2} \mathrm{CrO}_{7}, \mathrm{Cd}\left(\mathrm{NO}_{3}\right)_{2}$, $\mathrm{Ni}\left(\mathrm{NO}_{3}\right)_{2}, \mathrm{Cu}\left(\mathrm{NO}_{3}\right)_{2}, \mathrm{Zn}\left(\mathrm{NO}_{3}\right)_{2}, \mathrm{NaNO}_{3}, \mathrm{NaCl}, \mathrm{Na}_{2} \mathrm{SO}_{4}$ and $\mathrm{Na}_{2} \mathrm{HPO}_{4}$ were purchased from Sinopharm Chemical Reagent Co., Ltd (China). $\mathrm{K}_{2} \mathrm{CrO}_{7}$ was dissolved in deionized water (Molecular Co., $18.2 \mathrm{M} \Omega \mathrm{cm}$ ) to form a stock $\mathrm{Cr}(\mathrm{vI})$ solution of $1000 \mathrm{mg} \mathrm{L}^{-1}$. In addition, the multi-metal ion solution containing $\mathrm{Ni}(\mathrm{II}), \mathrm{Cd}(\mathrm{II}), \mathrm{Cu}(\mathrm{II}), \mathrm{Zn}(\mathrm{II})$ and $\mathrm{Cr}(\mathrm{VI})$ was prepared by dissolving the corresponding nitric salts mentioned above into deionized water. The co-anions solution was prepared by dissolving the corresponding sodium salts $\left(\mathrm{NaNO}_{3}, \mathrm{NaCl}, \mathrm{Na}_{2} \mathrm{SO}_{4}\right.$ and $\mathrm{Na}_{2} \mathrm{HPO}_{4}$ ) and $\mathrm{K}_{2} \mathrm{CrO}_{7}$ into deionized water to form bianion solutions, respectively. The organosilanes used include 3 -aminopropyltriethoxysilane (1N), $N$-( $\beta$-aminoethyl)- $\gamma$-aminopropylmethylbimethoxysilane $(2 \mathrm{~N})$ and $N$-3-trimethoxysilylpropyldiethylenetriamine $(3 \mathrm{~N})$, their structures were shown in Fig. 1. All silanes were used as received from Aladdin Industrial Co., Ltd (China).

\subsection{Synthesis of MA}

The MA was synthesized using a solvent-evaporation induced self-organization method which was a slightly modified recipe reported by Yuan et al. ${ }^{16}$ In a typical synthesis, $1.0 \mathrm{~g}$ P123 was dissolved in $10 \mathrm{~mL}$ of anhydrous ethanol at room temperature. Simultaneously, $1.6 \mathrm{~mL}$ of $67 \mathrm{wt} \%$ nitric acid was added into

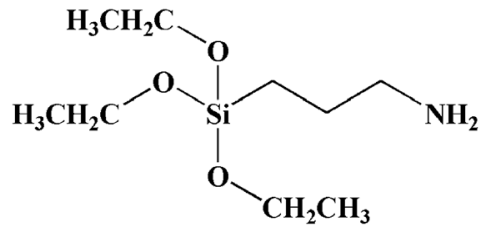

3-aminopropyltriethoxysilane<smiles>CO[Si](C)(CCCNCCN)OC</smiles>

$\mathrm{N}$-( $\beta$-aminoethyl)- $\gamma$-aminopropylmethylbimethoxysilane<smiles>CO[Si](CCCNCCNCCN)(OC)OC</smiles>

N-3-trimethoxysilylpropyldiethylenetriamine 
another $5 \mathrm{~mL}$ anhydrous ethanol, followed by adding $2.04 \mathrm{~g}$ aluminum isopropoxide under vigorous stirring to form a transparent solution, which was poured into the former P123 solution. Another $5 \mathrm{~mL}$ anhydrous ethanol was added, to totally transfer the remnant aluminum isopropoxide. The mixed solution was continuously stirred at room temperature for $5 \mathrm{~h}$, followed by solvent-evaporation procedure at $60{ }^{\circ} \mathrm{C}$ for $48 \mathrm{~h}$ in an oven under atmosphere to form a xerogel. The MA was obtained by calcination of the xerogel in a muffle furnace at $600{ }^{\circ} \mathrm{C}$ for $4 \mathrm{~h}$ with a ramp rate of $1^{\circ} \mathrm{C} \mathrm{min}^{-1}$.

\subsection{Grafting aminosilane onto MA}

In a typical synthesis, $1 \mathrm{~g}$ MA was dispersed in $30 \mathrm{~mL}$ anhydrous ethanol, in which $0.5 \mathrm{~g}$ amino organosilane was added under ultrasonic condition for $1 \mathrm{~min}$. The solution was then magnetically stirred for $1 \mathrm{~h}$ before centrifuge, and the precipitation was washed by anhydrous ethanol for 3 times to rinse redundant organics, dried in an oven for $2 \mathrm{~h}$ under $110^{\circ} \mathrm{C}$. The obtained sample was marked as MA- $x \mathrm{~N}$, where $x$ representing diverse amino organosilanes. For example, MA-2N represents that the sample was modified by $N$-( $\beta$-aminoethyl $)-\gamma$-aminopropylmethylbimethoxysilane $(2 \mathrm{~N})$, contain two amino groups in a pendant chain.

\subsection{Material characterizations}

The phase structures of the samples were determined by X-ray diffraction (XRD, Rigaku Ultima III, $\lambda=1.5406 \mathrm{~nm}$ ). Other physicochemical properties of the samples were characterized using transmission electron microscopy (TEM, JEM2100F), nitrogen physisorption (Micromeritics TriStar II 3020), Fourier transform infrared spectroscopy (FT-IR, Thermo Electron Scientific Instruments Nicolet 6700,400 to $4000 \mathrm{~cm}^{-1}$ ) and CHNS elemental analysis (Elementar Vario EL cube). In addition, X-ray photoelectron spectroscopy (XPS, PANalytical. B.V AXIOS) was used to investigate the chemical state of the samples. Zeta potential measurements were conducted with a zeta voltmeter (Zetasizer Nano ZS90). The residual Cr(vi) concentration was determined by colorimetric measurements on a Shimadzu II UV-vis spectrophotometry at $540 \mathrm{~nm}$ using the 1,5-diphenylcarbazide method. ${ }^{17}$ The concentrations of multimetal cations were determined using an inductively coupled plasma-atomic emission spectroscopy (ICP-AES, Perkin-Elmer Optima 4300DV).

\subsection{Adsorption studies}

Batch adsorption experiments were carried out to evaluate the adsorption performance of the samples. To investigate the effect of contact time during the adsorption process, $200 \mathrm{mg}$ sample was added to $100 \mathrm{~mL} \mathrm{Cr}(\mathrm{vI})$ solution of $50 \mathrm{mg} \mathrm{L}^{-1}$ (by diluting $1000 \mathrm{mg} \mathrm{L}^{-1} \mathrm{Cr}(\mathrm{vI})$ solution with water) and kept in a thermostatic oscillation at $25{ }^{\circ} \mathrm{C}$ and $180 \mathrm{rpm}$. The $\mathrm{pH}$ of the solution was maintained at 3 by adding $0.1 \mathrm{M} \mathrm{NaOH}$ or $0.1 \mathrm{M}$ $\mathrm{HNO}_{3}$ as the pH adjusting agent. The solution was sampled at different time points $(0,5,15,30,60,90,120$ and $180 \mathrm{~min})$ and filtered by a membrane of $0.45 \mu \mathrm{m}$ cellulose acetate membranes to execute further detection.
To investigate the adsorption isotherms, parameters including temperature, oscillating rate and $\mathrm{pH}$ were kept same and initial concentrations were varied instead of the sampling time points. The concentration of chromium in the initial or equilibrium solutions was determined by UV, and the residual concentrations of cations was determined by the 1,5-diphenylcarbazide method. The adsorption capacity was determined by the following equation:

$$
\text { Adsorption capacity } q_{\mathrm{e}}=\frac{\left(C_{0}-C_{\mathrm{e}}\right) V}{m}
$$

where $C_{0}$ and $C_{\mathrm{e}}\left(\mathrm{mg} \mathrm{\textrm {L } ^ { - 1 }}\right)$ are the initial concentration and equilibrium concentration of $\mathrm{Cr}(\mathrm{vI})$, respectively; $m(\mathrm{~g})$ is the mass of the adsorbent added in the solution; $V(\mathrm{~L})$ is the solution volume.

To investigate the selective adsorption for $\mathrm{Cr}(\mathrm{vI})$ before and after functionalization, $200 \mathrm{mg}$ sample was suspended in $100 \mathrm{~mL}$ mixture solution containing Ni(II), Cd(II), Cu(II), Zn(II) and $\mathrm{Cr}(\mathrm{vI})$ with concentration of $50 \mathrm{mg} \mathrm{L}^{-1}$, respectively, to form a multi-component metal ions solution. The solution $\mathrm{pH}$ was adjusted to 3 or 6 .

To investigate the interference of co-anions toward $\mathrm{Cr}(\mathrm{vI})$ adsorption, batch experiments were carried out by contacting the adsorbent with $100 \mathrm{~mL}$ binary solution at $\mathrm{pH} 3$ containing both $\mathrm{Cr}(\mathrm{vI})\left(50 \mathrm{mg} \mathrm{L}^{-1}\right)$ and one of the interferential anions (50 $\mathrm{mg} \mathrm{L}^{-1}$ ). The $\mathrm{Cr}(\mathrm{vI})$ percentage removal or adsorption efficiency was calculated using the following equation:

$$
\text { Removal efficiency }(\%)=\frac{C_{0}-C_{\mathrm{e}}}{C_{0}} \times 100
$$

where $C_{0}$ and $C_{\mathrm{e}}\left(\mathrm{mg} \mathrm{L}^{-1}\right)$ are the initial and equilibrium $\mathrm{Cr}(\mathrm{vI})$ concentrations, respectively.

To investigate the potential reusability of the samples, cyclic adsorption-regeneration tests were carried out. $\mathrm{Cr}(\mathrm{vI})$ was loaded onto the samples by putting $100 \mathrm{mg}$ adsorbents into $50 \mathrm{~mL}\left(2 \mathrm{~g} \mathrm{~L}^{-1}\right), 100 \mathrm{mg} \mathrm{L}^{-1} \mathrm{Cr}(\mathrm{vI})$ solution of $\mathrm{pH} 3$ to equilibrium. The $\mathrm{Cr}(\mathrm{vI})$ loaded sample was put in to $50 \mathrm{~mL}$ of $\mathrm{NaOH}$ solution $(0.05 \mathrm{M})$ and shaken for $3 \mathrm{~h}$ to desorb the $\mathrm{Cr}(\mathrm{vI})$, then washed with deionized water and dried in an oven at $80^{\circ} \mathrm{C}$ for $12 \mathrm{~h}$. The procedure was carried out for 5 treatment cycles.

\section{Results and discussion}

\subsection{Physicochemical properties}

The FT-IR results were shown in Fig. 2. It was found most band positions do not change after modification, suggesting that the original chemical structure of the alumina nearly remains stable. However, the peak intensities change and shift, indicating that partly chemical change occurs. For all samples, the peaks around $3445 \mathrm{~cm}^{-1}$ and $1640 \mathrm{~cm}^{-1}$ could be attributed to the stretching vibrations of $-\mathrm{OH}$ groups in the hydroxide structure as well as in physical adsorbed water. ${ }^{18}$ The broad peak from $500-750 \mathrm{~cm}^{-1}$ could be ascribed to $\mathrm{Al}-\mathrm{O}$ vibrations and $\mathrm{Al}-\mathrm{OH}$ wagging mode of the molecular water in amorphous alumina. ${ }^{18,19}$ Weak peaks at 1511 and $1411 \mathrm{~cm}^{-1}$ could be attributed to the trace of P123 added during the synthesis process. For all the samples, the peaks at 3443 and $1657 \mathrm{~cm}^{-1}$ 


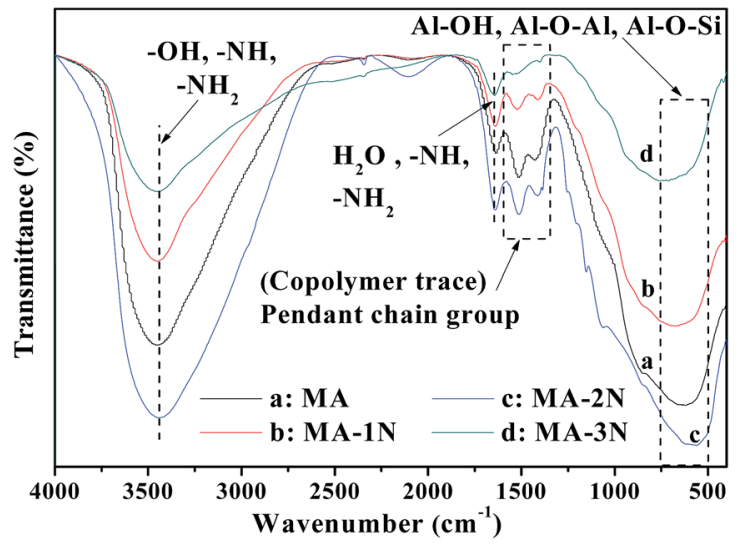

Fig. 2 FT-IR spectra of the samples.

belonging to stretching vibration and bending vibration, respectively for $-\mathrm{NH}$ and $-\mathrm{NH}_{2}$ become insignificant. This may be due to their merging with the peak of $-\mathrm{OH}$ and surface water. Likewise, the Al-O-Si peak also merges with the Al-O-Al band by virtue of closely spaced vibrational frequencies resulting from the insignificant atomic mass difference of $\mathrm{Al}$ and $\mathrm{Si}^{20,21}$

TEM images of the samples were shown in Fig. 3. They all show porous nature in the presence of P123 during the preparation process of alumina. Well-ordered pore network were observed in all samples with an average diameter of $\sim 8 \mathrm{~nm}$; the highly ordered hexagonal arrangement of pores along [001] (Fig. 3(b)-(d)) direction and the alignment of cylindrical pores along [110] (Fig. 3(a)) direction appear. ${ }^{16}$ After functionalization by $1 \mathrm{~N}, 2 \mathrm{~N}$ and $3 \mathrm{~N}$, respectively, no obvious damage or distortion of the pores occurs, and the highly ordered hexagonal arrangement of pores and cylindrical pores remain unchanged, which means that the mild functionalization process does not change the structural skeleton of MA. This is due to the peculiarity of the grafting method that functionalization mainly occurs on material surface because the size of organic groups is pretty small.

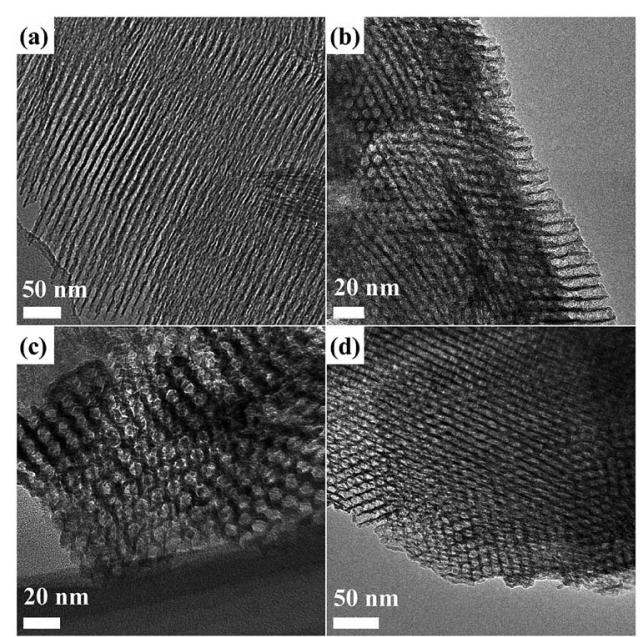

Fig. 3 TEM images of the samples: $M A(a), M A-1 N(b), M A-2 N(c)$ and $M A-3 N(d)$.
Their wide-angle and small-angle XRD patterns were shown in Fig. S1(a) and (b), $\dagger$ respectively. Fig. S1(a) $\dagger$ shows that the origin MA shows amorphous nature due to the fact that the crystalline state appears via calcination above $800{ }^{\circ} \mathrm{C} .{ }^{16,22}$ Fig. S1(b) $\dagger$ shows that all the samples show a very strong peak around $1.0^{\circ}$. Fig. S1 $\uparrow$ shows that the structure of MA does not obviously change after grafting, which accords with the results of TEM images in Fig. 3.

Their pore properties were investigated by $\mathrm{N}_{2}$ adsorption and desorption isotherms at $-196{ }^{\circ} \mathrm{C}$ as shown in Fig. 4. Their isotherms show type IV with distinct $\mathrm{H} 1$ type hysteresis loops which is the characteristic of mesoporous materials. In comparison with MA-1N and MA-3N, the $\mathrm{N}_{2}$ uptake of MA-2N is the highest, indicating an increase in the volume of mesopores. Their corresponding pore parameters were listed in Table 1. After grafting with organosilane containing two amino groups, MA-2N shows a specific surface area of $249.8 \mathrm{~m}^{2} \mathrm{~g}^{-1}$ and a pore volume of $0.59 \mathrm{~cm}^{3} \mathrm{~g}^{-1}$, which are higher than those of MA-1N, MA-3N and MA. Combining with the CHNS elemental analysis results listed in Table 2, it is explicable in terms of higher specific surface area of MA- $2 \mathrm{~N}$ than MA, as the grafting procedure could remove part of the residue carbon caused by incomplete combustion of P123, which leads to $0.7 \%$ carbon content of MA. This phenomenon of surface area increase is not conspicuous for MA- $1 \mathrm{~N}$ and MA- $3 \mathrm{~N}$ because the
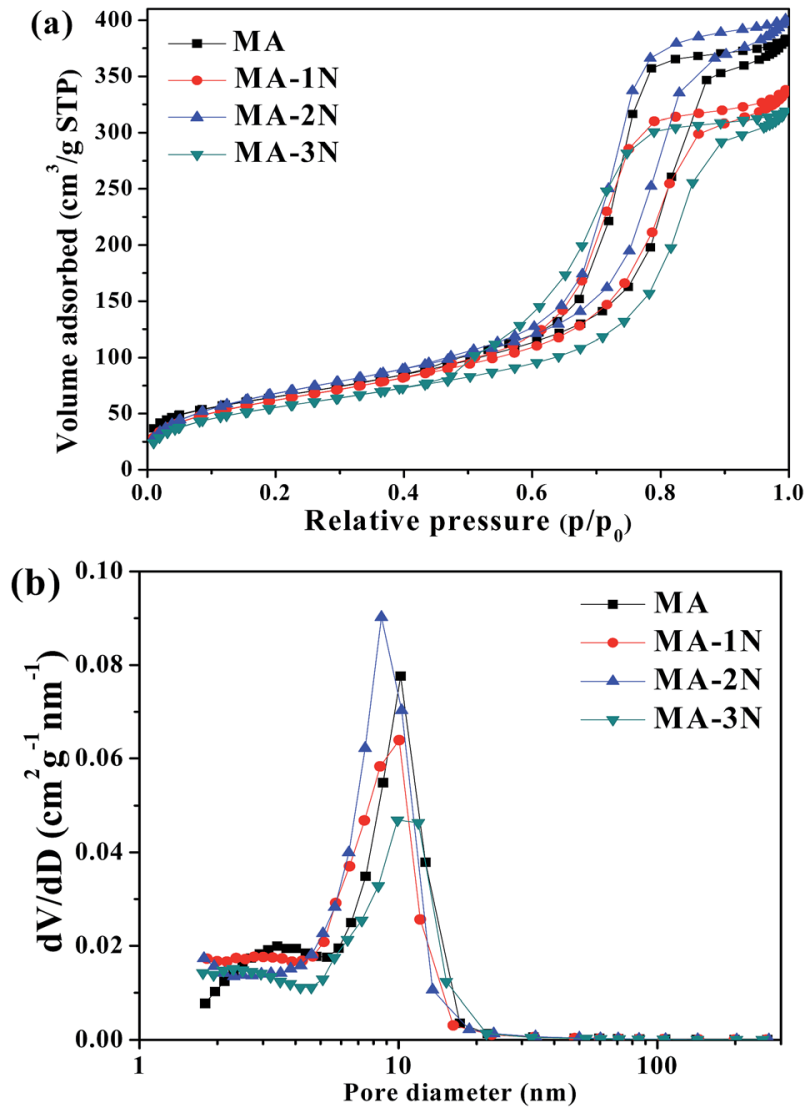

Fig. $4 \quad \mathrm{~N}_{2}$ adsorption-desorption isotherms (a) and the corresponding pore size distributions (PSD) (b) of the samples. 
Table 1 The pore structure parameters of the samples ${ }^{a}$

\begin{tabular}{llll}
\hline Sample & $d_{\mathrm{p}}, \mathrm{nm}$ & $S_{\text {BET }}, \mathrm{m}^{2} \mathrm{~g}^{-1}$ & $V_{\mathrm{t}}, \mathrm{cm}^{3} \mathrm{~g}^{-1}$ \\
\hline MA & 8.74 & 230.6 & 0.59 \\
MA-1N & 7.83 & 225.1 & 0.50 \\
MA-2N & 8.13 & 249.8 & 0.59 \\
MA-3N & 8.70 & 202.3 & 0.49
\end{tabular}

${ }^{a} d_{\mathrm{p}}=$ average pore size. $S_{\mathrm{BET}}=$ specific surface area calculated from adsorption data in the relative pressure range of $0.05-0.3 . V_{\mathrm{t}}=$ total pore volume calculated by integration of the PSD curve.

Table 2 CHNS elemental analysis results and zeta potential IEP

\begin{tabular}{lcccr}
\hline Sample & $\% \mathrm{C}$ & $\% \mathrm{H}$ & $\% \mathrm{~N}$ & IEP \\
\hline MA & 0.71 & 1.49 & 0.00 & 7.7 \\
MA-1N & 3.01 & 1.19 & 0.65 & 9.4 \\
MA-2N & 3.72 & 1.81 & 0.91 & 9.7 \\
MA-3N & 3.65 & 1.29 & 1.55 & 10.2
\end{tabular}

length of pendant groups and terminal oxygen-containing groups change..$^{23,24}$

The solution $\mathrm{pH}$ significantly influences the surface charge and the protonation degree of an adsorbent. The zeta potential titrations of the samples were shown in Fig. 5 and the isoelectric point (IEP) was listed in Table 2. It was found that the IEPs of all the amino organosilane modified samples shift to higher $\mathrm{pH}$ value of 9.4, 9.7 and 10.2, respectively, which are higher than 7.7 of MA. This indicates that the functionalized MA-1N, MA-2N and MA-3N surfaces were successfully modified with positively charged amino groups. After grafting, both of the raised positive potential and the right-shifted IEP forecast the better adsorption behaviour. In particular, a positive platform (marked in dashed frame) appears in all modified samples, showing buffer effect to defend acid and base. The buffer effect was brought by amino groups $\left(-\mathrm{NH}_{2},-\mathrm{NH}\right)$ in the pendant chain, and with increasing the amount of amino groups, the buffer effect was more notable. This means they have better acid and base resistance and wider $\mathrm{pH}$ range application, and is able to interact with the corresponding $\mathrm{Cr}(\mathrm{vI})$ species at different $\mathrm{pH}$

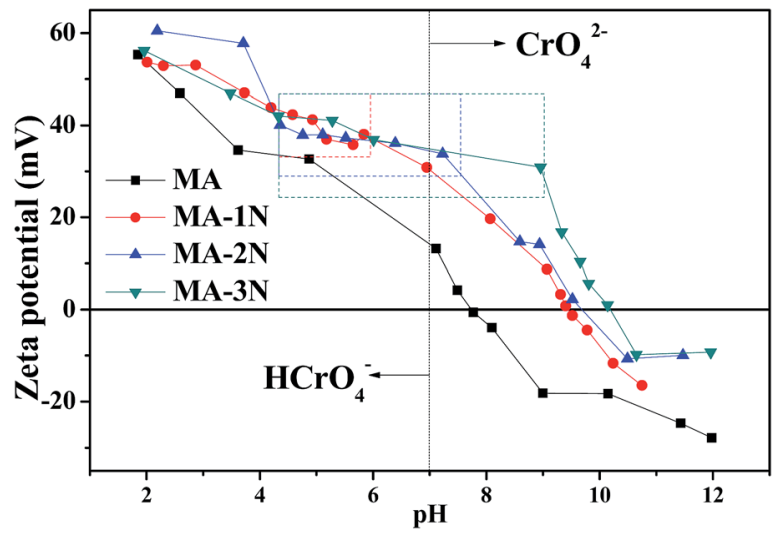

Fig. 5 Zeta potential analysis results of the samples. value. ${ }^{7,20,25,26}$ Hence, a more stable adsorption condition could be afforded during the adsorption process. In consequence, the initial $\mathrm{pH}$ value was selected as $\mathrm{pH}=3$; for the $\mathrm{Cr}(\mathrm{vI})$ species are composed more of $\mathrm{HCrO}_{4}{ }^{-}$, and the degree of protonation is more thoroughly, which are effective and profitable for adsorption of $\mathrm{Cr}(\mathrm{vI})$. At lower $\mathrm{pH}$, the adsorbent has the risk to be dissolved, causing mass loss.

\subsection{Adsorption behaviour of $\mathrm{Cr}(\mathrm{vI})$ ions}

3.2.1 Effect of contact time and adsorption kinetics. Adsorption kinetics of all the samples was carried out using $50 \mathrm{mg} \mathrm{L}^{-1} \mathrm{Cr}(\mathrm{vI})$ solution at $298 \mathrm{~K}$ and a $\mathrm{pH}$ of 3. As shown in
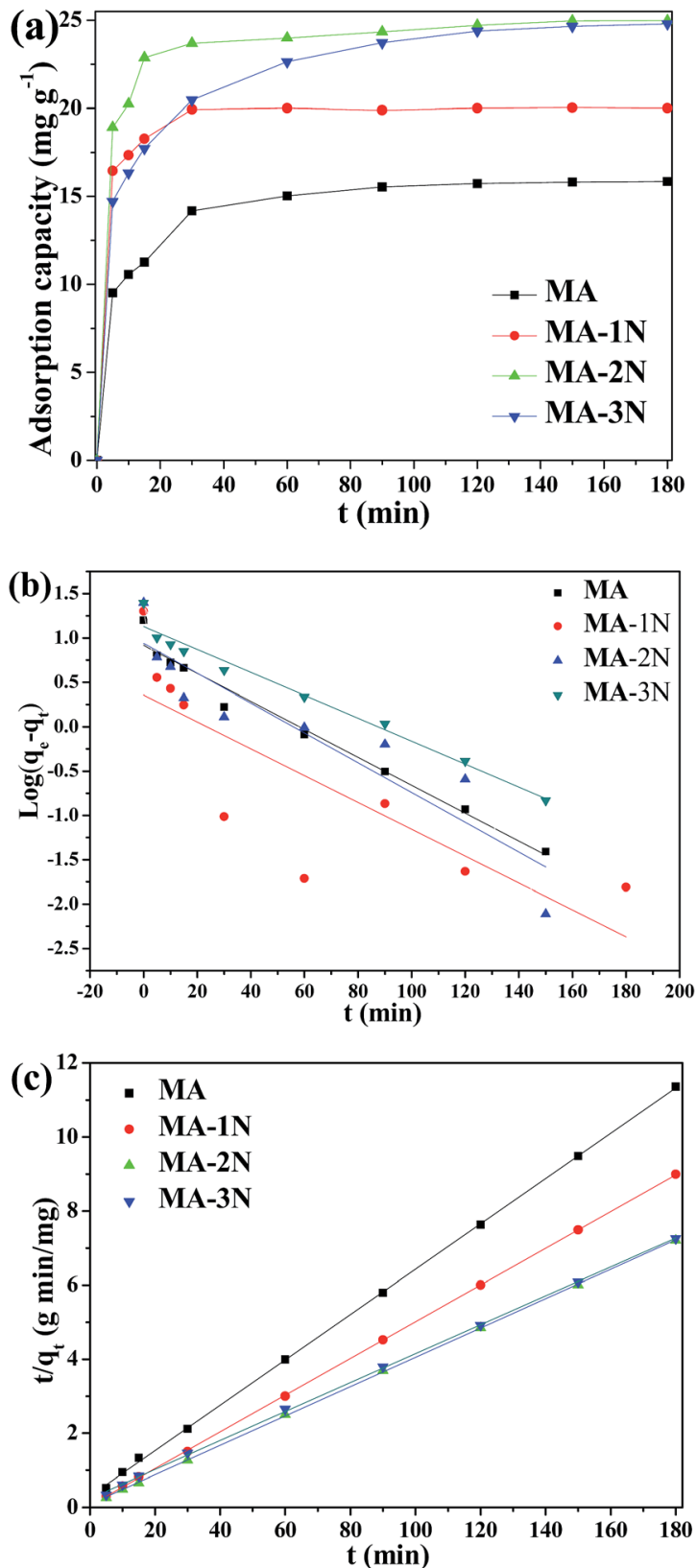

Fig. 6 Kinetic adsorption curves (a), linear fitting curves of the pseudo-first order (b) and the pseudo-second order (c) of the samples. 
Fig. 6(a), their adsorption capacities increase with increasing contact time. Most $\mathrm{Cr}(\mathrm{vI})$ was adsorbed within first $60 \mathrm{~min}$ for all the samples, and the amine functionalized samples (MA-1N, MA-2N and MA-3N) show much better adsorption performance than MA. The time needed to reach equilibrium is $180 \mathrm{~min}$, and the residual $\mathrm{Cr}(\mathrm{vI})$ concentration for $\mathrm{MA}-2 \mathrm{~N}$ is $<0.03 \mathrm{mg} \mathrm{L} \mathrm{L}^{-1}$, meeting the standard of water pollutants discharge of WHO. The rapid adsorption process in the beginning could be attributed to the greater concentration gradient and more available sites for adsorption. ${ }^{2}$ Then the adsorption rate becomes subdued owing to occupation of adsorption sites and a charge balance was reached between amine groups and $\operatorname{Cr}(\mathrm{vI}) .^{27}$

In order to investigate the rate-controlling mechanism of the adsorption process, the kinetic data were correlated to linear forms of the pseudo-first-order model and pseudo-second-order model as follows, respectively:

$$
\begin{gathered}
\log \left(q_{\mathrm{e}}-q_{t}\right)=\log q_{\mathrm{e}}-\frac{k_{1}}{2.303} t \\
\frac{t}{q_{t}}=\frac{1}{k_{2} q_{\mathrm{e}}^{2}}+\frac{t}{q_{\mathrm{e}}}
\end{gathered}
$$

where $q_{t}$ and $q_{\mathrm{e}}$ are the amounts of metal ions adsorbed at time $t$ (min) and equilibrium, respectively; $k_{1}\left(\mathrm{~min}^{-1}\right)$ and $k_{2}(\mathrm{~g}(\mathrm{mg}$ $\min )^{-1}$ ) are the pseudo-first-order and pseudo-second order rate constants of adsorption, respectively. The simulation data of pseudo-first order and pseudo-second order were listed in Table 3. The correlation coefficient $\left(R^{2}\right)$ of both models are $>0.9$, while the consistency of pseudo-second order simulation are more close to 1 , and the theoretical $q_{\mathrm{e}}$ of values pseudo-second order are more close to the experimental values, indicating that the adsorption process is more of chemical adsorption. ${ }^{28}$

3.2.2 $\mathrm{Cr}(\mathrm{vI})$ adsorption isotherms. The effect of the initial $\mathrm{Cr}(\mathrm{vI})$ concentration was investigated by contacting $200 \mathrm{mg}$ adsorbent with $100 \mathrm{~mL} \mathrm{Cr(vI)} \mathrm{solution} \mathrm{in} \mathrm{the} \mathrm{concentration}$ range of $20-500 \mathrm{mg} \mathrm{L}^{-1}$ with a contact time of $3 \mathrm{~h}$ and $\mathrm{pH}$ of 3 shown in Fig. 7. It was observed that with increasing the initial concentration, their adsorption capacities increase until reaching the equilibrium due to the limited active sites. Obviously, the amino functionalized samples show higher adsorption capacities than that of MA due to introducing $-\mathrm{NH}_{2}$ and $-\mathrm{NH}$ groups, and for $\mathrm{MA}-2 \mathrm{~N}$, its adsorption capacity is $137.86 \mathrm{mg} \mathrm{g}^{-1}$. When the initial concentration of $\mathrm{Cr}(\mathrm{vI})$ is below $50 \mathrm{mg} \mathrm{\textrm {L } ^ { - 1 }}$, its residual concentration qualifies the water pollutants discharge standard of WHO. Unexpectedly, although

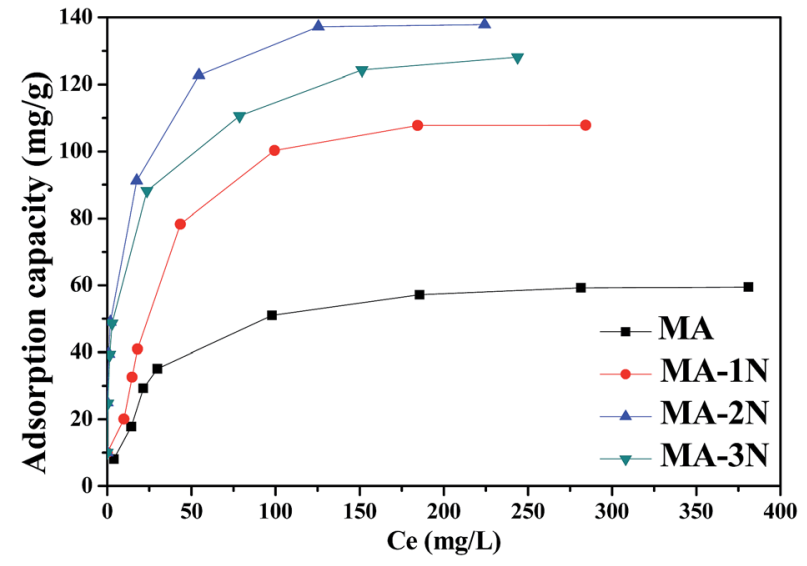

Fig. $7 \mathrm{Cr}(\mathrm{VI})$ adsorption isotherms of the samples.

MA-3N has higher amine loading, it does not perform better among the functionalized ones.

To further investigate the adsorption behaviour, their equilibrium adsorption was described by the Langmuir, Freundlich and Temkin models as follows:

$$
\begin{aligned}
& \text { Langmuir equation : } q_{\mathrm{e}}=\frac{k_{\mathrm{L}} q_{\mathrm{m}} C_{\mathrm{e}}}{1+k_{\mathrm{L}} C_{\mathrm{e}}} \\
& \text { Freundlich equation : } q_{\mathrm{e}}=k_{\mathrm{F}} C_{\mathrm{e}}^{\frac{1}{n}} \\
& \text { Temkin equation: } q_{\mathrm{e}}=B \ln k_{\mathrm{T}} C_{\mathrm{e}} \\
& \qquad B=\frac{R T}{b}
\end{aligned}
$$

where $C_{\mathrm{e}}$ is the equilibrium concentration of adsorbate in solution $\left(\mathrm{mg} \mathrm{L}^{-1}\right) ; q_{\mathrm{e}}$ and $q_{\mathrm{m}}\left(\mathrm{mg} \mathrm{g}^{-1}\right)$ are the amounts adsorbed at equilibrium and the maximum adsorption capacity for monolayer formation on adsorbent, respectively. $k_{\mathrm{L}}\left(\mathrm{L} \mathrm{mg}^{-1}\right)$ is the Langmuir constant related to the maximum adsorption capacity and the energy of adsorption. $k_{\mathrm{F}}$ is the Freundlich constant and $n$ is the heterogeneity factor. $\left(\ln k_{\mathrm{T}}\right)$ is correlated to the maximum binding energy, and $B$ was a constant related to the heat of adsorption.

The value of theoretical parameters and constants could be calculated from equation fitting, and the results were listed in Table 4. Their Langmuir isotherm correlates better for MA and MA-1N than the other two models $\left(R^{2}>0.995\right)$, while MA-2N

Table 3 The correlated kinetic parameters of $\mathrm{Cr}(\mathrm{vI})$ adsorption on the samples according to the pseudo-first-order and pseudo-second-order equation

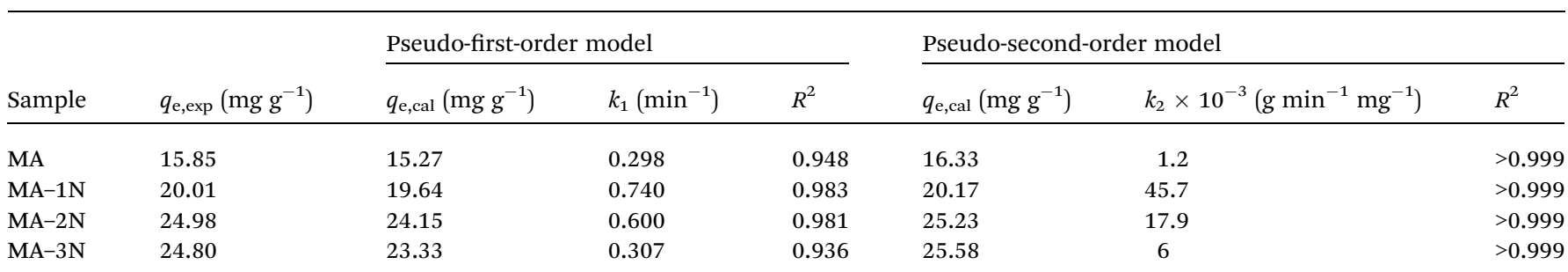


and MA-3N better fit Freundlich and Temkin models, respectively. For MA-1N, its surface was grafted with amino silane, which affords more adsorption sites than MA. Therefore its maximum adsorption capacity increases to $107.84 \mathrm{mg} \mathrm{g}^{-1}$ from $59.45 \mathrm{mg} \mathrm{g}^{-1}$ of MA. For MA-2N, with moderate amino content and higher surface area, its maximum adsorption capacity is $137.86 \mathrm{mg} \mathrm{g}^{-1}$ which is higher than its peer. Chun-Jae Yoo et $a{ }^{29}$ summarized that the amino organosilanes containing two amino groups in a chain has the larger average radius of silane domain, meaning that for two amine grafted sample like MA-2N, the amine coverage effect is prominent than MA-1N and MA-3N. This is another aspect which subsidiarily exhibits the superiority of MA-2N. The value of $n$ in the Freundlich isotherm is in the range of 1-10 which represents a good adsorption. Herein, the exponent of $n$ is $4.72(1<n<10)$, indicating that the adsorption system is favourable for $\mathrm{Cr}(\mathrm{vI})$ adsorption. The Temkin model assumes that the activity of the surface active sites is non-uniform, both strong and weak active sites exist. In addition, the interaction between the adsorbate and the adsorbent are uneven. On these premises, the adsorbates are adsorbed by strong active sites at the beginning. While with the surface coverage increases, the adsorption is getting weaker, and the required activation energy is growing, making the adsorption process harder. MA- $3 \mathrm{~N}$ was grafted with the longest functional group, and has the lowest surface area. Based on Temkin model, although MA-3N has the highest amino group content, its amine efficiency ( $\mathrm{mg} \mathrm{Cr}(\mathrm{vI})$ adsorbed $/ \mathrm{mmol} \mathrm{N}$ content) is only 1.2 which is much lower than 2.4 of MA-1N and 2.1 of MA-2N. This means that not all the amino groups of MA$3 \mathrm{~N}$ are involved in the adsorption process, probably due to the overlong pendant chain which hinders the movement of $\mathrm{Cr}$ species to the active sites.

\subsection{Multi-metal ion adsorption}

In water system, $\mathrm{Cr}(\mathrm{vI})$ often exist with some other metal ions. Therefore, adsorption selectivity of MA-2N and MA towards $\mathrm{Cr}(\mathrm{vI})$ was comparatively studied. The corresponding interference experiments in $100 \mathrm{~mL}$ solution containing $\mathrm{Cu}(\mathrm{II}), \mathrm{Zn}$ (II), $\mathrm{Ni}(\mathrm{II}), \mathrm{Cd}(\mathrm{II})$ and $\mathrm{Cr}(\mathrm{VI})$ of $50 \mathrm{mg} \mathrm{L}^{-1}$, respectively, at $\mathrm{pH}$ of 3 and 6 were carried out as shown in Fig. 8(a). For MA, it has lower adsorption capacity in the single component solution and does not show particular selectivity toward $\mathrm{Cr}(\mathrm{vI})$ in the multi-metal ion solution both at $\mathrm{pH}$ of 3 and 6 , while its adsorption capacities towards all the cations increase at a higher $\mathrm{pH}$ of 6 . For MA-2N, its adsorption capacity has little difference regardless the change of $\mathrm{pH}$ in the single component solution; while in the multi component solution, its adsorption capacity almost remains the same. The differences result from the amino groups of MA- $2 \mathrm{~N}$ and the discrepancy between metal ions. An important issue to be considered when discussing the stability of the metal-ligand complexes formed is related to Pearson's hard-soft, acid-base theory. Cd(II) is sorted as soft acid cation and tends to bind preferentially with ligands containing $\mathrm{S}$ (e.g. thiol groups), whereas the borderline acids cations $\mathrm{Zn}$ (II) and $\mathrm{Cu}(\mathrm{II})$ prefer to bond to ligands containing $\mathrm{N}$ donor atoms. In addition, solution $\mathrm{pH}$ also has a markedly influence on the sorption capacity, and at low $\mathrm{pH}$, cations are difficult to form stable coordination complex onto amino groups. Thus, on one hand, at low $\mathrm{pH}$, amino groups $\left(-\mathrm{NH},-\mathrm{NH}_{2}\right)$ on the surface of MA-2N are protonated, showing higher affinity towards $\mathrm{Cr}(\mathrm{VI})$ through electrostatic attraction and electrostatic repulsion toward cations. On the other hand, at high $\mathrm{pH}, \mathrm{Cu}$ (II) and $\mathrm{Zn}$ (II) show higher affinity towards amino groups containing $\mathrm{N}$ donor atoms. However, the affinity of MA-2N toward $\mathrm{Cr}(\mathrm{vI})$ is still higher than other metal ions for the special affinity between amino groups and $\mathrm{Cr}(\mathrm{VI})$. Likely, $\mathrm{Ni}$ (II) is unable to form stable coordination complex on MA-2N. As a result, amino functionalization can not only enhance the adsorption capacity, but also afford exclusive removal of $\mathrm{Cr}(\mathrm{vI}) .^{7,15,30,31}$

\subsection{Interference of co-anions}

Since industrial effluents often contain various additives such as inorganic salts, the effect of $\mathrm{SO}_{4}{ }^{2-}, \mathrm{HPO}_{4}{ }^{2-}, \mathrm{NO}_{3}{ }^{-}$and $\mathrm{Cl}^{-}$on their adsorption properties towards $\mathrm{Cr}(\mathrm{vI})$ was further studied as shown in Fig. 8(b). It was shown that their adsorption performance was undermined by $\mathrm{SO}_{4}{ }^{2-}$ and $\mathrm{HPO}_{4}{ }^{2-}$. Due to the suppressive effect of $\mathrm{SO}_{4}{ }^{2-}$, it tends to strike and detach $\mathrm{Cr}(\mathrm{vI})$ from adsorbents, thus the adsorbed $\mathrm{Cr}(\mathrm{vI})$ starts to mobile again in the solution rather than fix on the adsorbents surface. ${ }^{32}$ Meanwhile, phosphates possess affinity towards amino groups for its biological activity, ${ }^{33}$ therefore parts of active sites were taken by $\mathrm{SO}_{4}{ }^{2-}$ and $\mathrm{HPO}_{4}{ }^{2-}$, causing the loss of adsorption efficiency of $\mathrm{Cr}(\mathrm{vI}) \cdot \mathrm{NO}_{3}{ }^{-}$and $\mathrm{Cl}^{-}$only slightly affect the adsorption ability because of their lower ionic radius as well as electric valence state. However, the unique strong oxidative ability of $\mathrm{Cr}(\mathrm{vI})$ among the anions makes its overwhelming competitiveness during the adsorption process. Both $\mathrm{MA}-2 \mathrm{~N}$ and MA-3N exhibit better adsorption performance than MA, due to their higher amine content. These amino groups are able to affording much more adsorption sites than MA. The performance difference between MA- $2 \mathrm{~N}$ and MA-3N may result from the disparity of amine efficiency, and some amines on MA-3N

Table 4 Parameters of adsorption isotherms of the samples towards $\mathrm{Cr}(\mathrm{VI})$

\begin{tabular}{|c|c|c|c|c|c|c|c|c|c|c|}
\hline Adsorbent & $q_{\mathrm{e}, \exp }\left(\mathrm{mg} \mathrm{g}^{-1}\right)$ & $q_{\mathrm{m}}\left(\mathrm{mg} \mathrm{g}^{-1}\right)$ & $k_{\mathrm{L}}$ & $R^{2}$ & $k_{\mathrm{F}}$ & $n$ & $R^{2}$ & $\ln A$ & $B$ & $R^{2}$ \\
\hline MA-1N & 107.84 & 128.77 & 0.027 & 0.968 & 15.723 & 2.761 & 0.841 & -1.401 & 28.145 & 0.941 \\
\hline $\mathrm{MA}-2 \mathrm{~N}$ & 137.86 & 132.41 & 0.298 & 0.899 & 47.463 & 4.719 & 0.965 & 3.565 & 15.231 & 0.922 \\
\hline MA-3N & 128.09 & 120.58 & 0.262 & 0.932 & 39.068 & 4.405 & 0.976 & 2.081 & 17.040 & 0.993 \\
\hline
\end{tabular}



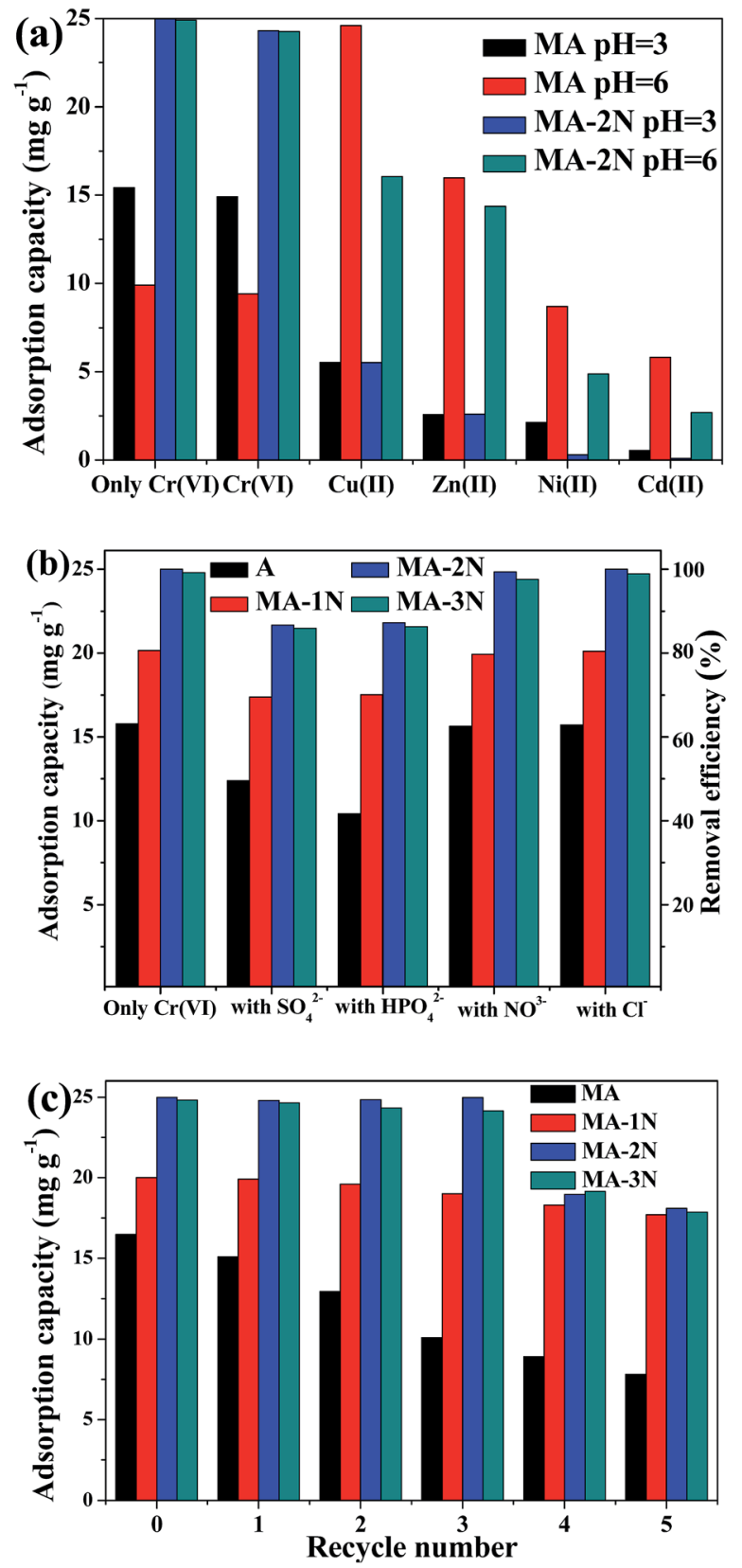

Fig. 8 Results of multi-metal ion adsorption (a), interference of coanions study (b) and regeneration study (c).

do not participate in the adsorption process, as mentioned above.

\subsection{Regeneration and reuse of the composites}

Regeneration and reuse ability is an important factor to evaluate the feasibility and cost-effectiveness of an adsorbent. The desorption agent was $50 \mathrm{~mL}, 0.05 \mathrm{M} \mathrm{NaOH}$ solution. The results were shown in Fig. 8(c). Compared to the functionalized samples, the adsorption ability of MA starts to decrease at the first re-adsorption procedure, and gradually decreases until its adsorption capacity only reaches $47.5 \%$ of its fresh ability. In contrast, the adsorption capacities of MA-1N, MA-2N and MA-
$3 \mathrm{~N}$ are relatively stable, and the adsorption capacities of MA- $2 \mathrm{~N}$ and MA-3N can remain stable for the first 3 cycles. This is because organosilane functionalized samples with $\mathrm{Si}-\mathrm{O}-\mathrm{Si}-\mathrm{R}$ bond are very stable, and $\mathrm{Al}-\mathrm{O}-\mathrm{Si}-\mathrm{R}$ bond are similar to $\mathrm{Si}-\mathrm{O}-$ Si-R bond. Furthermore, aminopropyl group could shield alumina and avoid its dissolution. ${ }^{25}$ The decrease of their adsorption capacities may result from the desorption treatments and re-adsorption processes or the strong oxidation ability of $\mathrm{Cr}(\mathrm{vI})$ species. $^{30}$

\subsection{XPS results analysis/chromium species on the composite} after adsorption and mechanism of $\mathbf{C r}(\mathrm{vr})$ removal

XPS analysis helps in identifying the oxidative state of various elements. The XPS full surveys of the MA and MA-2N were shown in Fig. S5. $\dagger$ New peaks attributed to N 1s $(399.9 \mathrm{eV})$ and Si $2 p(100 \mathrm{eV})$ were observed in Fig. 9(b). The high resolution XPS spectrum of $\mathrm{N}$ 1s and $\mathrm{C}$ 1s was shown in Fig. 9(a)-(c), and the two deconvoluted peaks were identified to $-\mathrm{NH}$ and $-\mathrm{NH}_{2}$. In Fig. 9(b), the C 1s spectrum of MA could be deconvoluted into three individual peaks at $284.5 \mathrm{eV}, 285.6 \mathrm{eV}$ and $289.6 \mathrm{eV}$, which were attributed to carbon groups $\left(\mathrm{C}=\mathrm{C}, \mathrm{CH}_{x}, \mathrm{C}-\mathrm{C}\right)$, hydroxyl groups or ethers $(-\mathrm{C}-\mathrm{OR})$ and carboxylic groups (-COOR), respectively. ${ }^{34}$ This verifies the imperfect combustion of the copolymer. For MA-2N, in Fig. 9(c), the C 1s spectrum could be similarly deconvoluted into three individual peaks at $284.5 \mathrm{eV}$, $285.6 \mathrm{eV}$ and $289.7 \mathrm{eV}$, and the peak area of carboxylic groups decreases. These results are in accordance with the results of FT-IR spectra, $\mathrm{N}_{2}$ adsorption-desorption and CHNS elemental analysis. The grafting process successfully combines MA with amino organosilane through chemical bond, and is able to simultaneously partly remove the residuary carbon brought by copolymers in the pore structures so that the surface area of MA-2N increases. With the nitrogen content of the grafting pendant group increasing, the nitrogen content from $0.65 \%$ of MA-1N to $1.55 \%$ of MA-3N was also improved. However, the adsorption capacity does not simply increase with the amino content, and MA-2N shows the fastest adsorption kinetics and the highest adsorption capacity among the modified samples (see Fig. 6 and 7). Furthermore, the same method was used to modify commercial alumina powder (purchased from Zibo Senchi Chemical Co., Ltd) and test its adsorption performance under the same condition in Section 3.2.1, shown in Fig. S2. $\dagger$ It was found that its adsorption performance was also enhanced after grafting of $2 \mathrm{~N}$.

It was reported that chromate forms a mixture of monoprotonated and non-protonated outer-sphere adsorption complexes on the hydrated $\gamma-\mathrm{Al}_{2} \mathrm{O}_{3}$ surface; ${ }^{35}$ the ethanol can solubilize all hydrogen-bonded species during the grafting process and subsequent washing procedures. ${ }^{36}$ So after a fixed time ( $1 \mathrm{~h}$ in our research), the amount of amino silanes immobilized on the surface of alumina were also fixed, and this immobilization depends on the number of silanol groups. The MA-2N possesses a medium molecule size, medium nitrogen content and the highest hydrogen content, which balance the amino groups and the hydroxyl groups. For MA-2N, the grafted model is more likely to form dimers by condensation (two 

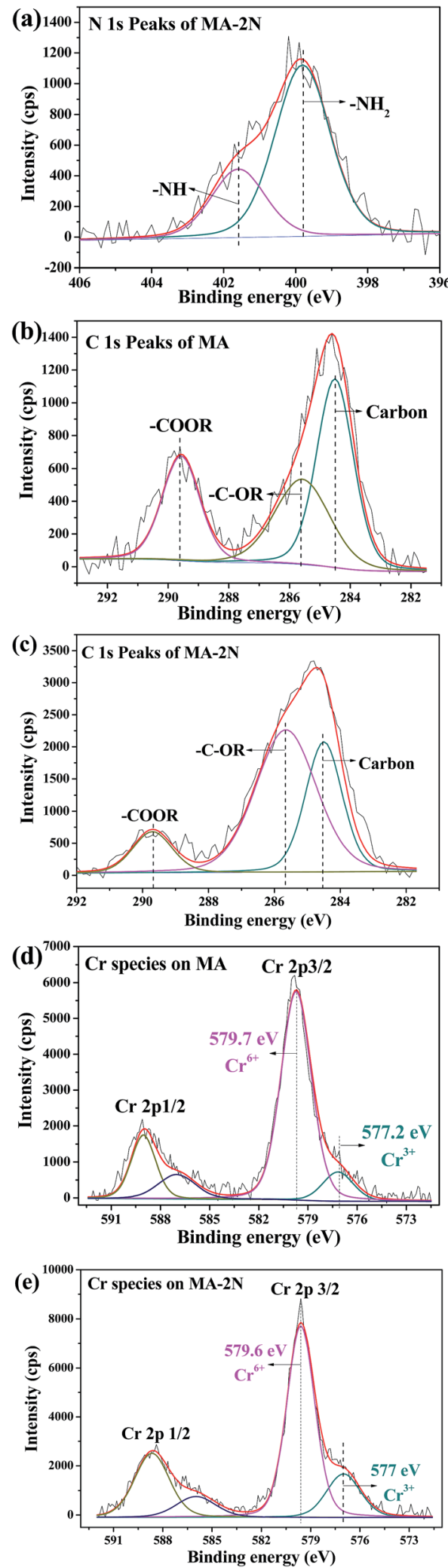

Fig. 9 High resolution of XPS spectra: $N$ 1s of $M A-2 N(a), C$ 1s of MA (b), $\mathrm{C}$ 1s of MA-2N (c), $\mathrm{Cr} 2 \mathrm{p}$ of MA after adsorption of $\mathrm{Cr}(\mathrm{vI})(\mathrm{d})$ and $\mathrm{Cr}$ $2 p$ of $M A-2 N$ after adsorption of $\mathrm{Cr}(\mathrm{vI})(\mathrm{e})$. covalent bonds to the surface) rather than long polymer of MA$1 \mathrm{~N}$ and MA-3N. However, the long polymer may turn out to present a coping effect of the alumina surface that $-\mathrm{NH}_{2}$ and $-\mathrm{OH}$ are unavailable for cooperative interactions. By virtue of $-\mathrm{OH}$, the protonated $-\mathrm{NH}_{2}$ and $-\mathrm{NH}-$ of $\mathrm{MA}-2 \mathrm{~N}$ are more activated and able to attract more $\mathrm{Cr}(\mathrm{vI})$ onto the composites surface, thus its adsorption driving force with quite faster adsorption kinetic is much higher than MA-1N and MA-3N, respectively. With increase of the equilibrium concentration of $\mathrm{Cr}(\mathrm{vI})$ in the solution, although the activated sites of MA-2N are gradually taken by adsorbates, the immobilization effect for adsorbates is still strong, resulting in its higher adsorption capacity than that of $\mathrm{MA}-1 \mathrm{~N}$ and $\mathrm{MA}-3 \mathrm{~N}$, respectively. Furthermore, because the balance between $-\mathrm{OH}$ and the protonated $-\mathrm{NH}_{2}$ and $-\mathrm{NH}$ - is different with variety of organosilanes, the adsorption isotherms of the samples varying from MA to MA-1N, MA-2N and MA-3N successively, change to fit the Freundlich model better. In addition, the moderate grafting amount was found as shown in Fig. S3. $\dagger$ This may be due to that lower loading amount limits the active sites and higher loading amount causes steric hindrance effect. All the factors result in the best performance of MA- $2 \mathrm{~N}$ among the amino organosilane modified samples.

After adsorption of MA and MA-2N towards $\mathrm{Cr}(\mathrm{vI})$, the peaks of $\mathrm{Cr} 2 \mathrm{p}$ emerges. The high resolution $\mathrm{Cr} 2 \mathrm{p}$ XPS patterns of both MA and MA-2N after adsorption were shown in Fig. 9(d) and (e). From Fig. 9(d), Cr 2p1/2 and $\mathrm{Cr} 2 \mathrm{p} 3 / 2$ peaks were located around $589 \mathrm{eV}$ and $579.7 \mathrm{eV}$ after differentationimitating analysis. The broad peak of $\mathrm{Cr} 2 \mathrm{p} 3 / 2$ was deconvoluted into two peaks at binding energies of $577.2 \mathrm{eV}$ and $579.7 \mathrm{eV}$, which were attributed to $\mathrm{Cr}(\mathrm{III})$ and $\mathrm{Cr}(\mathrm{VI})$, respectively. Whereas from Fig. 9(e), Cr 2p1/2 and $\mathrm{Cr} 2 \mathrm{p} 3 / 2$ peaks were located around $588.6 \mathrm{eV}$ and $579.6 \mathrm{eV}$, and the broad peak of $\mathrm{Cr}$ $2 \mathrm{p} 3 / 2$ was deconvoluted into two peaks at binding energies of $577 \mathrm{eV}$ and $579.6 \mathrm{eV}$, which shift to lower binding energy compared to the $\mathrm{Cr}$ states on MA. The results reveal that MA-2N is able to enhance the adsorption capacity of $\mathrm{Cr}(\mathrm{VI})$ and capability of detoxifying more $\mathrm{Cr}(\mathrm{VI})$ to $\mathrm{Cr}(\mathrm{III})$, according to the Handbook of X-ray Photoelectron Spectroscopy, $2^{\text {nd }}$ edition. $^{37}$ The functional groups on the surface of MA- $2 \mathrm{~N}$ participates in $\mathrm{Cr}(\mathrm{VI})$ adsorption. According to Pearson's principle of hard and soft acids and bases, chromium is categorized as a hard acid and nitrogen is classified as hard base. Herein, the $\mathrm{Cr}(\mathrm{vI})$ solution was adjusted to $\mathrm{pH}$ of 3 . At $\mathrm{pH}$ of 1-3, the predominant form of $\mathrm{Cr}(\mathrm{vI})$ is $\mathrm{HCrO}_{4}^{-}$, and the free energy for adsorbing $\mathrm{HCrO}_{4}{ }^{-}$is higher than $\mathrm{Cr}_{2} \mathrm{O}_{7}{ }^{2-}$ and $\mathrm{CrO}_{4}{ }^{2-}$. At the same time, groups such as $-\mathrm{OH},-\mathrm{NH}_{2}$ and $-\mathrm{NH}-$ are protonated to $-\mathrm{OH}_{2}{ }^{+}$, $-\mathrm{NH}_{3}{ }^{+}$and $-\mathrm{NH}_{2}{ }^{+}$-. Due to its higher surface area and being positively charged of MA-2N, more $\mathrm{Cr}(\mathrm{vI})$ are adsorbed on its surface by electrostatic attraction. The interaction could be depicted as follows: $:^{2,38}$

$$
\begin{gathered}
-\mathrm{NH}_{3}{ }^{+}+\mathrm{HCrO}_{4}{ }^{-} \rightarrow \mathrm{NH}_{3}{ }^{+}-\mathrm{HCrO}_{4}{ }^{-} \\
2\left(-\mathrm{NH}_{2}{ }^{+}-\right)+\mathrm{CrO}_{4}{ }^{2-} \rightarrow-\mathrm{NH}_{2}{ }^{+}-\mathrm{CrO}_{4}{ }^{2-}-\mathrm{NH}_{2}{ }^{+}- \\
\mathrm{Al}-\mathrm{OH}^{+}+\mathrm{HCrO}_{4}^{-} \rightarrow \mathrm{AlOCrO}_{3}{ }^{-}+\mathrm{H}_{2} \mathrm{O} \text { (mono-dentate) }
\end{gathered}
$$




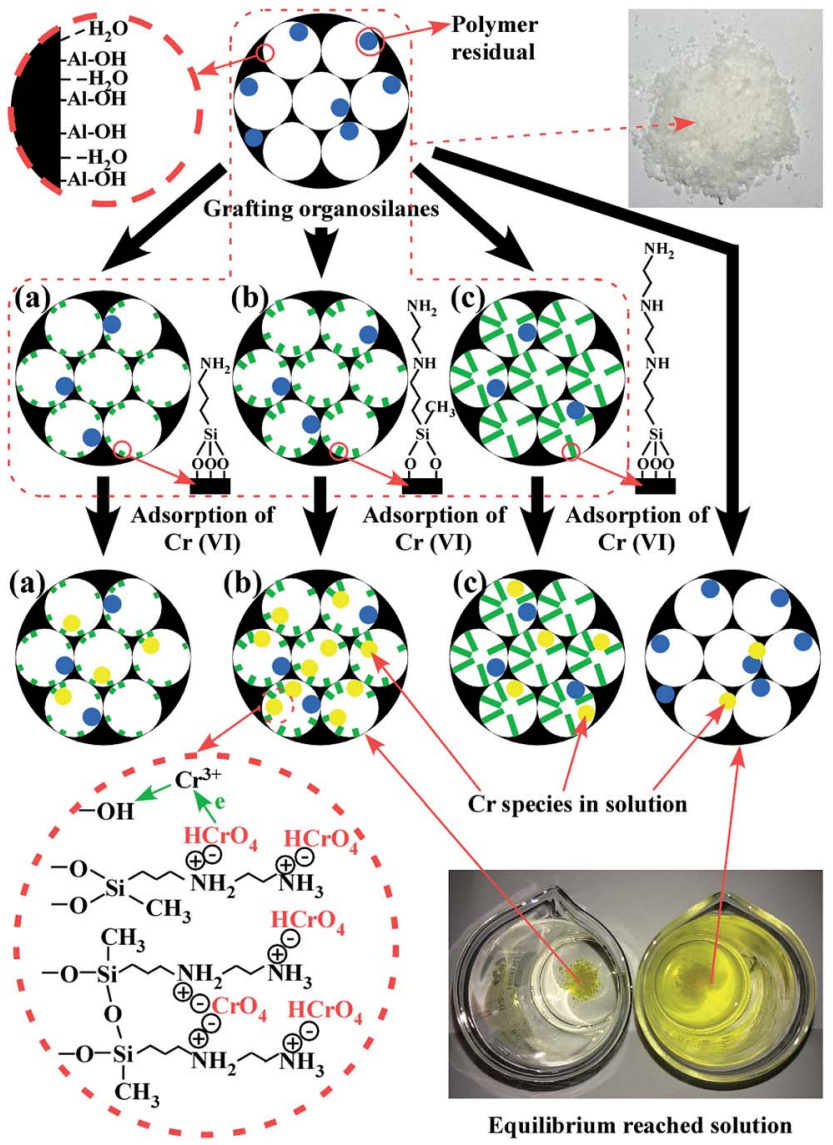

Fig. 10 MA grafting with (a) $1 \mathrm{~N}$, (b) $2 \mathrm{~N}$ and (c) $3 \mathrm{~N}$ and overall mechanism of $\mathrm{MA}-2 \mathrm{~N}$ toward $\mathrm{Cr}(\mathrm{VI})$ adsorption.

$2\left(\mathrm{Al}-\mathrm{OH}^{+}\right)+\mathrm{HCrO}_{4}^{-} \rightarrow 2(\mathrm{AlO}) \mathrm{CrO}_{2}+2 \mathrm{H}_{2} \mathrm{O}$ (bi-dentate) (12)

Monodentate ligand and bidentate ligand form, thus the surface concentration of $\mathrm{Cr}(\mathrm{vI})$ increase. Then, $\mathrm{Cr}(\mathrm{vI})$ was reduced to $\mathrm{Cr}$ (III) by adjacent electron donor, after which $\mathrm{Cr}(\mathrm{III})$ was in co-precipitation of the adsorbents, mixed with adsorbed $\mathrm{Cr}(\mathrm{vI})$. In general, the reaction was carried on as follows: ${ }^{2}$

$$
\begin{gathered}
\mathrm{HCrO}_{4}{ }^{-}+7 \mathrm{H}^{+}+3 \mathrm{e} \leftrightarrow \mathrm{Cr}^{3+}+4 \mathrm{H}_{2} \mathrm{O} \\
\mathrm{Cr}^{3+}+4 \mathrm{H}_{2} \mathrm{O} \leftrightarrow \mathrm{Cr}(\mathrm{OH})^{2+}+\mathrm{H}^{+}
\end{gathered}
$$

The adsorption mechanism was depicted in Fig. 10. The digital picture insets are the batch solutions that reach equilibrium after contacting $200 \mathrm{mg}$ MA and MA-2N with $100 \mathrm{~mL}$ $\mathrm{Cr}(\mathrm{vI})$ solution of $50 \mathrm{mg} \mathrm{L}^{-1}$ and $\mathrm{pH}$ of 3 . The solution treated by MA-2N on the left becomes colourless, while the solution treated by MA on the right is still bright yellow. Therefore, MA$2 \mathrm{~N}$ is obviously more efficacious than MA.

\section{Conclusions}

MA grafted by amino organosilanes with a simple, energy saving and environmentally friendly method was successfully prepared and assessed for the removal of $\mathrm{Cr}(\mathrm{vI})$ ions from aqueous solution. The functionalization and loading of amino organosilanes was tracked by FT-IR, XPS and CHNS elemental analysis. The adsorption rate and adsorption capacity were significantly enhanced after functionalization, and the residual concentration of $\mathrm{Cr}(\mathrm{vI})$ is under the limit of WHO. Amino functionalization endows the MA with far more better reuse ability, exclusive adsorption affinity toward $\mathrm{Cr}(\mathrm{vr})$ in multi-metal ions and multi anions solution. The adsorption ability of amino functionalized samples is a comprehensive effect which results from the combination of surface area and the amount of amino groups. The results show that the amino functionalized MA-2N from $N$ ( $\beta$-aminoethyl)- $\gamma$-aminopropylmethylbimethoxysilane with fairly good reusability is a good candidate which could be used for remediation and selective extraction of $\mathrm{Cr}(\mathrm{vI})$ from wastewater.

\section{Conflicts of interest}

There are no conflicts to declare.

\section{Acknowledgements}

This work was financially supported by the National Natural Science Foundation of China (21476179), 2016 Wuhan Yellow Crane Talents (Science) Program and one hundred talents project of Guangzhou University.

\section{References}

1 Y. Z. Yan, Q. D. An, Z. Y. Xiao, S. R. Zhai, B. Zhai and S. Zhan, J. Mater. Chem. A, 2017, 5, 17073.

2 L. F. Zhang, W. Xia, L. Xin and W. Q. Zhang, J. Mater. Chem. A, 2015, 3, 331.

3 W. Q. Cai, L. J. Tan, J. G. Yu, M. Jaroniec, X. Q. Liu, B. Cheng and F. Verpoort, Chem. Eng. J., 2014, 239, 207.

4 Y. G. Xia, L. Zhang, Y. Wang, X. L. Jiao and D. R. Chen, Mater. Lett., 2015, 143, 294.

5 G. L. Li, Z. S. Zhao, J. Y. Liu and G. B. Jiang, J. Hazard. Mater., 2011, 192, 277.

6 X. Q. Chen, W. K. Ching, K. F. Lam, W. Wei and K. L. Yeung, J. Phys. Chem. C, 2016, 120, 18365.

7 I. Sierra and D. Pérez-Quintanilla, Chem. Soc. Rev., 2013, 42, 3792.

8 W. Q. Cai, J. G. Yu and M. Jaroniec, J. Mater. Chem., 2010, 20, 4587.

9 E. Kumar, A. Bhatnagar, W. Hogland, M. Marques and M. Sillanpää, Chem. Eng. J., 2014, 241, 443.

10 V. Linsha, P. S. Suchithra, A. Peer Mohamed and S. Ananthakumar, Chem. Eng. J., 2013, 220, 244.

11 W. Q. Cai, L. J. Tan, J. G. Yu, M. Jaroniec, X. Q. Liu, B. Cheng and F. Verpoort, Chem. Eng. J., 2014, 239, 207.

12 X. Feng, G. E. Fryxell, L. Q. Wang, A. Y. Kim and J. Liu, Science, 1997, 276, 923.

13 M. Etienne and A. Walcarius, Talanta, 2003, 59, 1173.

14 Z. Zhu, X. X. Yang, L.-N. He and W. Li, RSC Adv., 2012, 2, 1088. 
15 S. A. Idris, K. Alotaibi, T. A. Peshkur, P. Anderson and L. T. Gibson, J. Colloid Interface Sci., 2012, 386, 344.

16 Q. Yuan, A. X. Yin, C. Luo, L. D. Sun, Y. W. Zhang, W. T. Duan, H. C. Liu and C. H. Yan, J. Am. Chem. Soc., 2008, 130, 3465.

17 J. S. Cao and W. X. Zhang, J. Hazard. Mater., 2006, 132, 213.

18 T. Kim, J. B. Lian, J. M. Ma, X. C. Duan and W. J. Zheng, Cryst. Growth Des., 2010, 10, 2928.

19 G. X. Xue, X. Huang, N. Zhao, F. K. Xiao and W. Wei, RSC $A d v .$, 2015, 5, 22972.

20 W. A. W. Razali, V. K. A. Sreenivasan, E. M. Goldys and A. V. Zvyagin, Langmuir, 2014, 30, 15091.

21 L. F. Koong, K. F. Lam, J. Barford and G. McKay, J. Colloid Interface Sci., 2013, 395, 230.

22 W. Q. Cai, J. G. Yu, C. Anand, A. Vinu and M. Jaroniec, Chem. Mater., 2011, 23(5), 1147.

23 J. M. Rosenholm and M. Lindén, Chem. Mater., 2007, 19, 5023.

24 P. C. Pinheiro, D. S. Tavares, A. L. Daniel-da-silva, C. B. Lopes and E. Pereira, ACS Appl. Mater. Interfaces, 2014, 6, 8274.

25 M. Sakeye and J.-H. Smått, Langmuir, 2012, 28, 16941.

26 Y. Pang, G. M. Zeng, L. Tang, Y. Zhang, Y. Y. Liu, X. X. Lei, Z. Li, J. C. Zhang, Z. F. Liu and Y. Q. Xiong, Chem. Eng. J., 2011, 175, 222.
27 P. Luo, J. S. Zhang, B. Zhang, J.-H. Wang, Y.-F. Zhao and J.-D. Liu, Ind. Eng. Chem. Res., 2011, 50, 10246.

28 H. Li, D.-L. Xiao, H. He, R. Lin and P.-L. Zuo, Trans. Nonferrous Met. Soc. China, 2013, 23, 2657.

29 C. J. Yoo, L. C. Lee and C. W. Jones, Langmuir, 2015, 31, 13350.

30 A. S. K. Kumar, S.-J. Jiang and W.-L. Tseng, J. Mater. Chem. A, 2015, 3, 7044.

31 X. Chen, K. F. Lam, Q. Zhang, B. Pan, M. Arruebo and K. L. Yeung, J. Phys. Chem. C, 2009, 113, 9804.

32 C. H. Wu, S. L. Lo and C. F. Lin, Colloids Surf., A, 2000, 166, 251.

33 L. Li, W. Y. Gu, J. Liu, S. Y. Yan and Z. P. Xu, Nano Res., 2015, 8, 682 .

34 Y. J. Qi, B. Y. Song and Y. Qi, RSC Adv., 2016, 6, 102428.

35 E. J. Elzinga, Y. Z. Tang, J. McDonald, S. DeSisto and R. J. Reeder, J. Colloid Interface Sci., 2009, 340, 153.

36 T. G. Waddell, D. E. Leyden and M. T. DeBello, J. Am. Chem. Soc., 1981, 103, 5303.

37 J. F. Moudler, W. F. Sticle, P. E. Sobol and K. D. Bomben, in Handbook of XPS, ed. J. Chastain, Perkin-Elmer, Eden Prairie, MN, 1992, p. 41.

38 L. Luo, W. Q. Cai, J. B. Zhou and Y. Li, J. Hazard. Mater., 2016, 318, 452. 